\title{
Usability Analysis of an Educational Data Mining Framework
}

\author{
Usability Analysis of an Educational Data Mining Framework
}

Vitória Maria Pena Mendes ${ }^{1}$ (D) orcid.org/0000-0002-2280-7687

Raniel Gomes Silva 1 (iD) orcid.org/0000-0003-4874-3447

Alexandre Magno Andrade Maciel ${ }^{1}$ (D) orcid.org/0000-0003-4348-9291

${ }^{1}$ Escola Politécnica de Pernambuco, Universidade de Pernambuco, Recife, Brasil.

E-mail do autor principal: Vitória Mendes vmpm@ecomp.poli.br

\section{Resumo}

Este artigo apresenta uma análise de usabilidade de um framework de mineração de dados educacionais chamado FMDEV. O objetivo geral é entender como este framework pode fornecer uma melhor usabilidade para usuários que não possuem um conhecimento prévio de Ciência de Dados. Por meio de uma avaliação heurística, problemas de usabilidade foram revelados e testes de usabilidade confirmaram que esses problemas estavam afetando a jornada do usuário ao interagir com o sistema. Os resultados desta análise indicam que é possível alcançar uma aproximação entre ferramentas de mineração de dados e profissionais não técnicos quando seu comportamento como usuários reais é levado em consideração no processo de desenvolvimento do sistema.

Palavras-Chave: Mineração de Dados Educacionais; Usabilidade; Experiência de Usuário.

\begin{abstract}
This paper presents a usability analysis of an educational data mining framework called FMDEV. The overall goal is to understand how this framework can provide a better usability to users that do not have a prior knowledge of Data science. Through a heuristic evaluation, usability problems were revealed, and usability tests confirmed these problems were affecting the user's journey while interacting with the system. The results of this analysis indicates that it is possible to achieve an approximation between data mining tools and non-technical professionals when their behavior as real users are taken into account in the system development process.
\end{abstract}

Key-words: Educational Data Mining; Usability; User Experience. 


\section{Introduction}

In the past few years, Learning Management Systems (LMSs) have been widely adopted in the field of Distance Education. These systems provided a quick access to educational tools and contents that were integrated into the same space. With this in mind, a significant amount of educational data was being stored and the research area of Educational Data Mining (EDM) came up to generate knowledge by analyzing this data. Data Mining applied specifically to education has been increasing, even though the pace is not as fast as in e-commerce [1].

Essentially, EDM merges concepts of Computer Science and Statistics in order to construct insights about educational information. Considering the fact that Education is also a key area of EDM, people with non-technical skills should be able to deal with EDM tools. However, nowadays it seems that one needs to know Data Mining, Learning Analytics and even Machine Learning Algorithms to use EDM. A larger fraction of the population can improve the state of education through EDM [2].

With that in mind, the processes of building EDM tools need to consider an unusual target audience in order to expand its use, traditionally it was assumed that technical understanding was a must. But, one way to understand how to successfully reach this audience is delivering a system that was built thinking about the user experience of these new users that don't really have a prior knowledge of Data science in general.

User Experience (UX) has been playing a major role in development teams, no matter which development stage you're involved. UX evaluation provides a better understanding of the end users and helps you recognize design mistakes [3]. Some studies have focused on the importance of a positive user experience of LMSs. Usability of e-learning systems is crucial to improve the acceptance of these systems for students, the main target audience of LMSs [4].

In this paper we aim to analyze how an EDM framework can elevate its usability so non-technical users can have a better user experience. That being said, we are going to evaluate a system called FMDEV (Framework de Mineracão de Dados Educacionais). This framework was developed to generate models through Data Mining and Machine Learning to provide relevant information about educational phenomena. The main objective is to explore FMDEV's level of compliance with established usability heuristics by identifying usability problems, and then validate through a usability test if the found problems were actually affecting the target audience experience.

\section{Background}

This section presents theoretical fundamentals to facilitate the understanding of this paper through a literature review and concepts definitions.

\subsection{Educational Data Mining}

Educational Data Mining Educational Data Mining (EDM) is a field that studies educational data sets to recognize a way to deal with educational issues. Using Statistics, Data Mining and Machine Learning techniques, EDM grants the possibility of having useful information to a broad number of stakeholders. Data Mining applied in variant domains have their particular obstacles and EDM is no different [1]. The fact that educational phenomena and additional pedagogical aspects need to be considered might require unique Data Mining techniques.

Moreover, the knowledge provided by Learning Management Systems data contributes to a better understanding of student behavior when user centered design is taken into account [5]. In this way, Education, Data Mining and Design need to work together to turn EDM more accessible.

\subsection{User Experience (UX)}

The investigation of user behavior while utilizing a product or service has been happening ever since computers were not popular. With the advance of computer systems that became a part of everyday life, Human-Computer Interaction ( $\mathrm{HCI}$ ) emerged to study how people interact with computer technology. Later on, [Norman et al. 1995] came up with the term User Experience to describe the human interface research they have done at Apple.

User experience goes beyond a pretty and modern user interface, it focus in the entire user journey to make the user interaction process simple and intuitive. An experience might be something subjective by the fact that every person has a unique story and perception of the world. Despite this subjectivity, the experiences were once thought by somebody and that they had a common goal in mind in order to grant a pleasant experience [6].

There are many facets that influence the user experience. UX has to consider more than the context of a user interacting with some content [7], a great 
experience contemplates a few more items and that is why he developed de UX honeycomb that is illustrated in Figure 1.

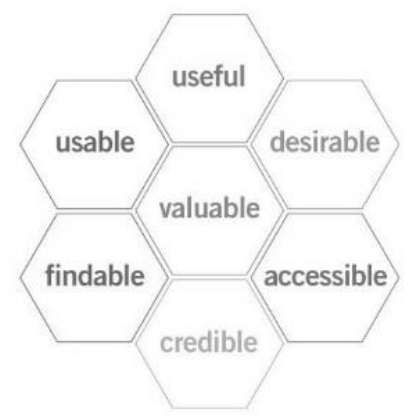

Figure 1: User Experience Honeycomb. Fonte: Morville (2004) [7].

These are the seven factors that affect UX, a system needs to be useful, usable, findable, credible, desirable, accessible and valuable. Useful because it presents a purpose or objective, usable to help users achieve their goals, findable so users can easily find the content they need, credible to deliver confidence, desirable because aesthetics brings value, accessible to reach people with different abilities, and valuable to deliver benefits to the users. Thinking about all of these, this paper is focusing on the Useful factor since we are analyzing the usability of a system.

\subsection{Nielsen's 10 Usability Heuristics}

Heuristics are a manner of problem solving based on previous experiences. Its techniques are an simple way to identify issues based on a preceding set of rules. In user experience design a heuristic evaluation is a method to find usability problems when an evaluator checks an interface. There are multiple sets of heuristics that have been created such as Shneiderman eight golden rules [8] and Bastien and Scapin ergonomic criteria [9]. In this study, to follow heuristics well established in the market, Jakob Nielsen's 10 usability heuristics were chosen.

Jakob Nielsen conducted a study to synthesize a new set of heuristics so that the maximum number of usability problems that appear in real systems could be taken into consideration [10]. These heuristics were proposed decades ago, but it remains applicable to modern softwares. Jakob Nielsen is one of the founders of the Nielsen Norman Group, a UX research firm. Nielsen presents recent content and the 10 heuristics displayed there are the following [11]:
1. Visibility of system status;

2. Match between system and the real world;

3. User control and freedom;

4. Consistency and standards;

5. Error prevention;

6. Recognition rather than recall;

7. Flexibility and efficiency of use;

8. Aesthetic and minimalist design;

9. Help users recognize, diagnose and recover from errors;

10. Help and documentation.

\section{Materials and Methods}

To verify the usability of FMDEV in order to propose an improved experience to our new users, the analysis was performed in two steps: A heuristic evaluation and an usability test.

\subsection{The Interface}

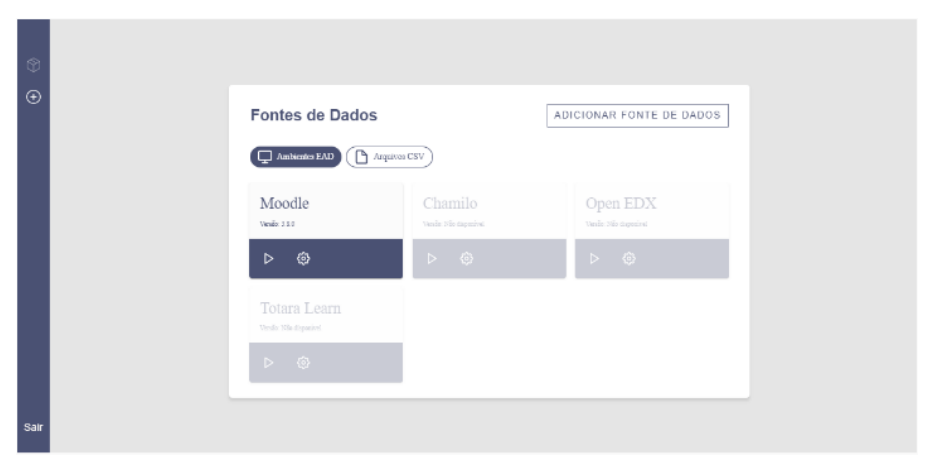

Figure 2: FMDEV's Home Page. Fonte: The author.

Figure 2 shows the interface of FMDEV's home page. This framework was made thinking about an unusual target audience in order to democratize the use of EDM. It gives the users the possibility to connect with LMSs like Moodle through an API and also add separate data sources from .csv files.

The goal is after selecting the data the user has to separate which data goes to the pre-processed dataset and then train this data to output a data model. All of this is meant to be done without a deep knowledge of data mining techniques and machine learning algorithms. It is supposed to be an easy way to apply data mining to education data. 


\subsection{Subjects}

The heuristic evaluation was done by the author of this project as the evaluator. Regarding the test script we firstly had to define the user persona in order to recruit the right participants. A user persona represents the target audience aimed to be analyzed in our research. So, that would be non-technical users who manage LMSs. A total of fourteen people, contacted through indication and LMSs groups, showed interest in participating. Only five finished the necessary steps of the test to be counted as a valid participant.

\subsection{Scenarios}

Two scenarios were proposed to the participants so they could perform it during the usability test. In the first scenario the user would try to save a model using data already available, such as Moodle, and the second one was to save a model with sample data given in an attached file. Both scenarios did not have any specific task that needed to be detailed, the main idea was to set a goal and see how the users were behaving in order to achieve it while using the system.

\subsection{Procedure}

\subsubsection{Heuristic Evaluation}

The first step of the evaluation consisted in the examination of the system interface by the evaluator. The FMDEV had an implemented version that was hosted online to facilitate the tests, so the person had access to the system to start the heuristics evaluation. By using the FMDEV, the person had to follow these steps when an usability problem was found: Write the page and component where it occurred, describe the problem, correlate the problem with one of the 10 heuristics, rate the severity of the problem and propose a possible solution.

All of the information about the found usability problems were stored in a spreadsheet. The template is presented in the results section. One thing that is worth mentioning is how the severity rate of a usability problem was decided. The severity rate of a usability problem combines three factors: frequency, impact and persistence [12]. From that, a rating scale from 0 to 4 measures the problem severity. Table 1 shows a description of each rate number that he proposed.

The act of choosing a value from the rating scale brings up some degree of subjectivity from the evaluator [12].
Table 1: Severity rate of usability problems.

\begin{tabular}{c|l}
\hline Rate & \multicolumn{1}{|c}{ Description } \\
\hline 0 & I don't agree that this is a usability problem at all \\
\hline 1 & $\begin{array}{l}\text { Cosmetic problem only: need not be fixed unless extra } \\
\text { time is available on project }\end{array}$ \\
\hline 2 & $\begin{array}{l}\text { Minor usability problem: fixing this should be given low } \\
\text { priority }\end{array}$ \\
\hline 3 & $\begin{array}{l}\text { Major usability problem: important to fix, so should be } \\
\text { given high priority }\end{array}$ \\
\hline 4 & $\begin{array}{l}\text { Usability catastrophe: imperative to fix this before } \\
\text { product can be released }\end{array}$
\end{tabular}

\subsubsection{Usability Test}

Being compliant with usability heuristics is an effective way to cover issues and prevent further problems to the end users. On the other hand, a great user experience can only be delivered if the system was tested [13]. Testing is the only way to see if a site really works. Through a usability test it's possible to understand the behavior of real users by observing how they perform a certain activity.

There are different types of usability testing, it can be in-person or remote, moderated or unmoderated. Despite the type or the platform used, a test involves a participant that performs tasks given by a facilitator. In this study we performed a remote unmoderated test. Figure 3 shows the information flow of this kind of test.

The choice of a remote test was mainly made because of the COVID-19 pandemic. In-person tests would be difficult and not recommended considering the social distancing policies and protocols. To that end, an unmoderated test was preferred over a moderated since the sessions could be done at the pace of the participant without a specified time.

\section{Remote Unmoderated: Flow of Information}
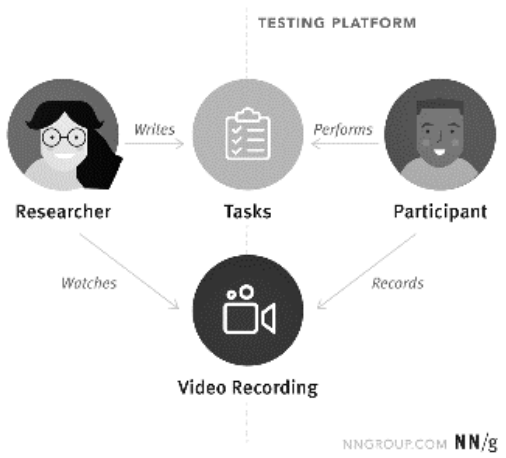

Figure 3: Remote Unmoderated Test. Fonte: Moran (2019) [14]. 
Regarding the test script we firstly had to define the user persona to recruit the right participants. A user persona represents the target audience aimed to be analyzed in our research. So, that would be nontechnical users who manage LMSs. After getting in contact with the prospects, a willing participant received an email with the following content: $A$ presentation video about the FMDEV. The video is only to show the purpose of the framework and introduce its features. It is not a tutorial, because that could comprise the test results. A brief information of the type of the test. To record the screen the test environment was configured with Smartlook, a tool that automatically capture users' events while they interact with the system. Then the credentials to access the test environment was provided and two main tasks were proposed. First the user would try to save a model using data already available, and the other one was to save a model with a sample data given in an attached file. Lastly, the user had to answer a survey.

The survey had fifteen questions and an optional open space to additional comments. The first section had five questions about general information to learn a bit further of the user's background. The other section was thought to generate a quantitative indicator of the system usability. With that in mind, the ten remaining questions were from the System Usability Scale (SUS) proposed by J. Brooke as a method to measure usability [15]. Taking all of this into account, when a user completed the last step of the test responding to the survey, the facilitator would start analyzing the video recordings and survey responses.

\section{Results}

This section presents the results collected from the whole usability analysis. The heuristics evaluation brought up usability problems. From the usability test there is the data generated in the Smartlook tool from the video recordings and FMDEV's usability score collected through the survey that was previously mentioned.

\subsection{Usability Problems}

After finishing the heuristics evaluation a few usability problems were found, Table 2 shows the number of errors of each heuristic analyzed.
Table 2: Number of usability problems per heuristic.

\begin{tabular}{c|c}
\hline Heuristic & $\begin{array}{c}\text { Number of } \\
\text { problems }\end{array}$ \\
\hline Visibility of system status & 1 \\
\hline $\begin{array}{c}\text { Match between system and } \\
\text { the real world }\end{array}$ & 1 \\
\hline User control and freedom & 1 \\
\hline Consistency and standards & 2 \\
\hline Error prevention & 1 \\
\hline Recognition rather than recall & 1 \\
\hline Flexibility and efficiency of use & 1 \\
\hline Aesthetic and minimalist design & 0 \\
\hline Help users recognize, diagnose, \\
and recover from errors
\end{tabular}

Regarding the visibility of system status a problem was found in a list of indicators that the user chose to be preprocessed, this list was too long some of the time and it was not showing properly all the indicators. This problem was classified with a severity rate of two as a minor usability problem. A possible solution to this is the implementation of a pagination.

Considering the match between system and the real world, when a user had to configure the model training the parameters had a specific name that was not familiar to the users' language. It was a minor problem that could be fixed by adding tooltips to each parameter explaining their meaning and role in the training process.

User control and freedom allows the user to have options to come back easily to a previous state of the system. FMDEV's users that clicked in the toolbar to see the saved models lost all their progress unless they had an ongoing training. This has a severity rate of four indicating that it is a usability catastrophe. One way to avoid it would be adding a confirmation step before redirecting the page or providing a way to save the current state so the user could come back to it later after navigating to the saved model's section.

The evaluation of consistency and standards brought up two problems. The first one was when the user saved a model it needed to add some text to a section called model details, later when the user moved to the saved models page this text was in a section called model description. This is a cosmetic problem only and it has a severity rate of one. This 
would be easily solved by adding the same label to both text sections. The second problem was about the FMDEV's logo in the toolbar, when the user hovered over it a click pointer was shown but when the user clicked nothing happened. A standard used in a broader number of web systems is that when the user clicks in the logo the system redirects to the home page, so this could be a possible solution to this minor usability problem.

Looking at the error prevention heuristic, the problem found was when selecting the indicators, the user needed to choose the target indicator in order to continue. If the user forgot to select it a message would pop up, but one way to make it simple and prevent this kind of error is to automatically add the target indicator to the list. This is a minor usability problem with a severity rate of two. When the user looked at a saved model, they needed to remember which parameters were utilized in the training since it was not shown in the saved model page. So, in order to be compliant with the recognition rather than recall heuristic and overcome a severity rate two problem it would be better to show training information and relevant data related to the saved model.

Observing the flexibility and efficiency of use of the system, a minor usability problem was found. The user does not have any way of filtering the chosen indicators, even with a pagination to present these items in a better way it would be great to have a few filters available.

FMDEV's aesthetics is simple and it does not have a lot of pages and dialogues, so through this heuristics evaluation it was not found any problem worth to mention that it is not even a usability problem at all. Regarding the error recovering there was a severity rate four problem that prevented users utilizing the Windows operating system to upload a .csv file. The last heuristic is about help and documentation and currently there is no user documentation or help area. This was classified as a major problem with a severity rate of three. A FAQ, first log in onboarding and short tutorial videos should be considered to solve this problem.

\subsection{Smartlook Information}

Navigating through the system and evaluating its compliance with the 10 Nielsen's Heuristics gave a nice perspective of a few problems the users would encounter while utilizing the system. So, to validate these problems and see if they were actually something relevant to our target users the user testing was made. After the usability test the data collected by Smartlook was analyzed and most of the problems shown in the previous section happened with the users.

The video recordings and metrics revealed that there were rage clicks in the logo where seemed to be a clickable area, a few users received the error message to choose the target indicator that was forgotten and needed to be selected, a significant amount of time were spent looking at the list of chosen indicators, users lost they progress clicking not only at the saved models button at the toolbar but also with a misclick at the add button too. These are just some of the cases that could be confirmed through observation.

Other feedback was sent in the survey and new problems like unusual errors were found only by the usability test. Figure 4 shows a heatmap of FMDEV's main page to show the most clicked areas of the page. Inside Smartlook the heatmap is interactive and can indicate the exact number of clicks in each of these areas.

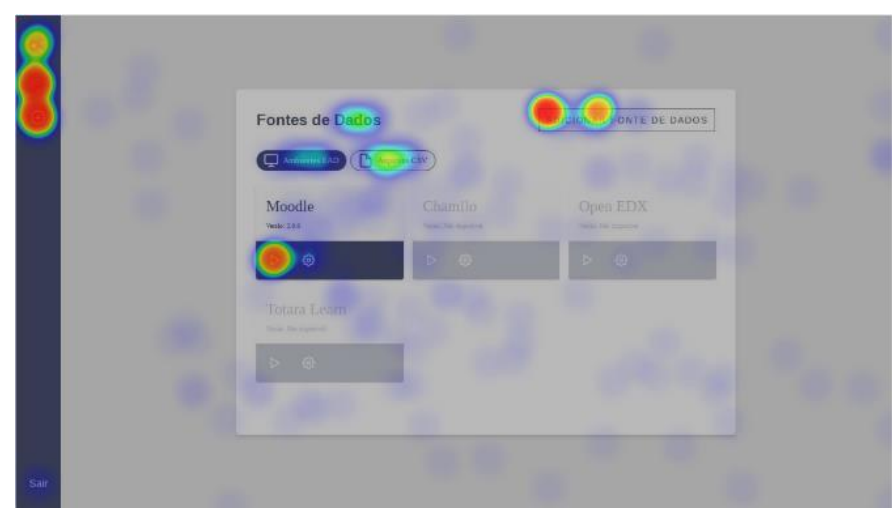

Figure 4: FMDEV's Heatmap. Fonte: The author.

\subsection{Usability Score}

The System Usability Scale was calculated based on the questions listed in Table 3. Each question could be answered within the range of 1 to 5 where 1 means that you strongly disagree with the question and 5 that you strongly agree. To calculate the score the questions were divided into even and odd. Based on the question parity the answer value would have a different number on the score calculation. With that in mind, the answer value of Q1, Q3, Q5, Q7 and Q9 needed to be decreased by 1 . On the other hand, even question answers were the result of 5 minus the value. Therefore, the value of 5 is considered as 4 if it was the answer to an odd question and 0 if the question was even. 
Table 3: SUS Score Questions.

\begin{tabular}{c|l}
\hline Number & \multicolumn{1}{c}{ Question } \\
\hline Q1 & $\begin{array}{l}\text { I think that I would like to use this system } \\
\text { frequently }\end{array}$ \\
\hline Q2 & I found the system unnecessarily complex \\
\hline Q3 & I thought the system was easy to use \\
\hline Q4 & $\begin{array}{l}\text { I think that I would need the support of a } \\
\text { technical person to be able to use this system }\end{array}$ \\
\hline Q5 & $\begin{array}{l}\text { I found the various functions in this system were } \\
\text { well integrated }\end{array}$ \\
\hline Q6 & $\begin{array}{l}\text { I thought there was too much inconsistency in } \\
\text { this system }\end{array}$ \\
\hline Q7 & $\begin{array}{l}\text { I would imagine that most people would learn to } \\
\text { use this system very quickly }\end{array}$ \\
\hline Q8 & I found the system very cumbersome to use \\
\hline Q9 & I felt very confident using the system \\
\hline Q10 & $\begin{array}{l}\text { I needed to learn a lot of things before I could } \\
\text { get going with this system }\end{array}$ \\
\hline
\end{tabular}

After that, all the new score values were summed up and then multiplied by 2.5 to make the SUS score. Table 4 shows the original score that the five users who participated in the usability test gave to each question and the SUS score as result for their answers.

Table 4: FMDEV's SUS Score.

\begin{tabular}{l|l|l|l|l|l|l|l|l|l|l|l}
\hline User & Q1 & Q2 & Q3 & Q4 & Q5 & Q6 & Q7 & Q8 & Q9 & Q10 & $\begin{array}{l}\text { SUS } \\
\text { Score }\end{array}$ \\
\hline U1 & 4 & 2 & 3 & 5 & 4 & 4 & 2 & 4 & 2 & 5 & 37.5 \\
\hline U2 & 3 & 4 & 2 & 5 & 5 & 3 & 3 & 3 & 4 & 4 & 45 \\
\hline U3 & 3 & 5 & 2 & 5 & 4 & 4 & 3 & 4 & 2 & 5 & 27.5 \\
\hline U4 & 5 & 3 & 3 & 5 & 1 & 1 & 3 & 1 & 5 & 2 & 67.5 \\
\hline U5 & 4 & 1 & 5 & 2 & 2 & 2 & 5 & 1 & 4 & 2 & 85 \\
\hline
\end{tabular}

Adding the SUS score of all participants and dividing them by 5 gives us an average score of 52.5 . Bangor proposed an adjective rating corresponding to the mean SUS score ratings [16]. Then, according to Figure 5 FMDEV has an OK usability score.

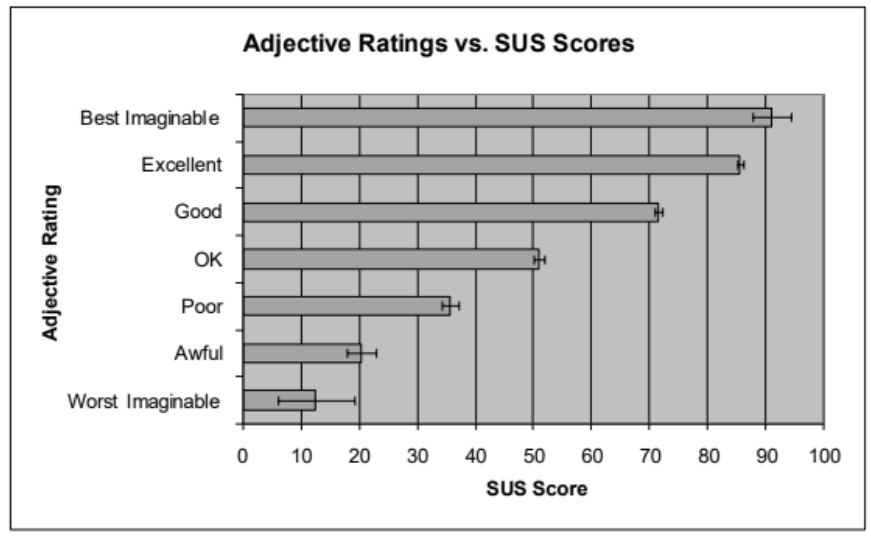

Figure 5: Adjective Rating. Fonte: Bangor et al. (2009) [16]

\section{Conclusions and Future Work}

The results demonstrate that an usability analysis is crucial to understand your users and check if their previously designed journey is being accomplished. Even though a Heuristic evaluation is an easy way to find problems throughout the whole system and most of these problems were truly happening with the users, it does not discard the possibility of a user testing. A usability test session with the target users is still important to validate your system and its use in the real world.

These findings suggest that the FMDEV has the potential to establish a better user experience to non-technical users by investigating their behavior and solving the issues that are in the way of achieving their goals in the system. An OK rating brings up the possibility of further analysis. Regardless of solving all the problems mentioned in this project, future research should look for a slightly bigger number of users participating in the tests to receive new feedback and revalidate the SUS Score. Another interesting topic for future work is the integration with a Learning Analytics Dashboard to provide an adequate visualization of the indicators used to train the models and even a better way to present the saved models statistics and information.

\section{References}

[1] ROMERO, C. and VENTURA, S. (2010). Educational data mining: A review of the state of the art. Systems, Man, and Cybernetics, Part C: 
Applications and Reviews, IEEE Transactions on, 40:601 - 618.

[2] ROMERO, C., VENTURA, S., PECHENIZKIY, M., and BAKER, R. (2010). Handbook of Educational Data Mining. CRC Press, 1st edition.

[3] GORDILLO, A., BARRA, E., AGUIRRE, S., and QUEMADA, J. (2014). The usefulness of usability and user experience evaluation methods on an elearning platform development from a developer's perspective: A case study. IEEE Frontiers in Education Conference (FIE) Proceedings, pages 18.

[4] HARRATI, N., BOUCHRIKA, I., and A. TARI, A. L. (2016). Exploring user satisfaction for elearning systems via usage-based metrics and system usability scale analysis. Comput. Hum. Behav. 61, page 463-471.

[5] BANDEIRA, M. ,SANTOS, N., RIBEIRO, V., GAVIÃO NETO, W. (2016). Mineração De Dados:

A Nova Maneira De Compreender O Comportamento Do Usuário Do Ensino A Distância. Congresso Brasileiro de Pesquisa e Desenvolvimento em Design, pages 2536-2548.

[6] TEIXEIRA, F. (2014). Introdução e boas práticas em UX Design. Casa do Código, Vila Mariana, São Paulo, 1st edition.

[7] MORVILLE, P. (2004). User experience design. [Online; accessed May-14-2020].

[8] SHNEIDERMAN, B., PLAISANT, C., COHEN, M., JABOCS, S., ELMQVIST, N., and DIAKOPOULOS, N. (2016). Designing the User Interface: Strategies for Effective Human-Computer Interaction. Pearson, 6th edition.

[9] BASTIEN, J. and SCAPIN, D. (1992). A validation of ergonomic criteria for the evaluation of human-computer interfaces. International Journal of Human-Computer Interaction, 4(2):183-196.

[10] NIELSEN, J. (1994a). Enhancing the explanatory power of usability heuristics. Proc. ACM CHI'94 Conf. (Boston, MA, April 24-28), pages 152-158.
[11] NIELSEN, J. (2005). 10 usability heuristics for user interface design. [Online; accessed May14-2020].

[12] NIELSEN, J. (1994b). Severity ratings for usability problems. [Online; accessed June-102020].

[13] KRUG, S. (2014). Don't make me think, revisited : a common sense approach to Web usability. New Riders, Berkeley, Calif., 3rd edition.

[14] MORAN, K. (2019). Usability testing 101. [Online; accessed July-01-2020].

[15] BROOKE, J. (1996). A 'quick and dirty' usability scale. in jordan p.w., thomas b., weerdmeester b.a., mcclelland i. I. (eds.) usability evaluation in industry. Taylor Francis, London, pages 189-194.

[16] BANGOR, A., KORTUM, P., and MILLER, J. (2009). Determining what individual sus scores mean: Adding an adjective rating scale. JUS Journal of Usability Studies, 4:114- 123. 